\title{
Water-mediated adhesion of oil sands on solid surfaces at low temperature
}

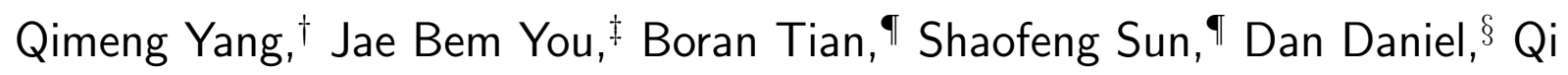 \\ Liu $^{\dagger}$ and Xuehua Zhang*, ${ }^{*}$ \\ $\dagger$ Department of Chemical and Materials Engineering, University of Alberta, Alberta T6G \\ 1H9, Canada \\ $\ddagger$ Department of Chemical Engineering, Kyungpook National University, Daegu 41566, \\ Republic of Korea \\ 9Imperial Oil, Calgary, Alberta T2C 4P3, Canada \\ $\S$ Institute of Materials Research and Engineering (IMRE), Agency for Science, Technology \\ and Research (A*STAR), Singapore 138634, Singapore \\ E-mail: xuehua.zhang@ualberta.ca
}

\begin{abstract}
Adhesion of frozen granular materials on solid surfaces creates various problems for surface cleaning, reduces the carrying capacity of vehicles, and increases energy consumption for in-land transportation. Here we report that water content determines the adhesion strength of oil sands on solid surfaces at temperature of $-2.5{ }^{\circ} \mathrm{C}$ to $-20{ }^{\circ} \mathrm{C}$. Our measurements by X-ray micro-computed tomography revealed that water forms capillary bridges between the sand particles and the solid substrate and more air gaps at the interface between oil sands and the substrate are filled with interstitial water at a higher content. We experimentally measured the minimal force required to push the frozen oil sands off the substrate and identified that the adhesion strength increased
\end{abstract}


linearly with water content from $4 \%$ to $14 \%$ on both rubber and steel substrate. For short freezing time at a fixed water content, lowering the temperature increased the adhesion strength on the steel substrate. Fouling from a layer of bitumen or asphaltenes aggravated the adhesion of oil sands on steel. A theoretical model was proposed to rationalize the linear relationship between water content and the adhesion strength, based on the contact area between ice and the substrate. We also found an effective method to reduce the adhesion of oil sands by spraying a little amount of anti-freezing liquid on the substrate. Our approach may reduce the energy consumption in transport and processing of wet granular materials, and potentially save manpower and the cost from cleaning in industrial operations. The insight from our work may have wide applicability to many natural/industrial processes, such as soil formation, food processing, and porous structures in ice crystal-templating nanomaterials synthesis by freezing-drying.

\section{Introduction}

Freezing of wet granular materials is important for many processes, ranging from landscape and soil formation in nature ${ }^{1}$ to food storage in cold chain, ${ }^{2,3}$ preservation of biological materials and systems at low temperature, ${ }^{4}$ and porous materials synthesis by templating ice crystals. ${ }^{5}$ Phase change of interstitial water trapped in confined spaces plays an essential role in all the above processes. For instance, the cycles of freezing and thawing of water determines weathering of rocks in soil formation. ${ }^{6}$ In food processing, the texture of ice creams is strongly correlated with ice crystals in the matrix of fat, proteins, and bubbles. ${ }^{7}$ Ice nucleation and sublimation in a freezing-drying process creates porous structures in the framework of materials, producing not only soft porous polymers like hydrogels or aerogels, but also hard materials of ceramics, metal or metal organic frameworks. ${ }^{5}$ However, in many other cases, accumulation of frozen granular materials on solid surfaces (such as wheels of cars and trucks, ship hulls, ${ }^{8}$ wings of air crafts,,${ }^{9,10}$ power lines, ${ }^{11}$ and wind turbines ${ }^{12,13}$ ) is 
highly undesirable, and it leads to deterioration of vehicles, increased energy consumption in transport, and additional cost and manpower for cleaning and maintenance. Despite its importance, it remains unclear what determines the adhesion of granular materials on solid surfaces at low temperature.

For ice accumulated on a solid surface, the physical and chemical properties of the solid substrate determine the adhesion strength. ${ }^{14-16}$ On flat surfaces, Meuler et al ${ }^{17}$ (and others $^{18-20}$ ) showed that the ice adhesion strength is linearly proportional to the Young-Dupre work of adhesion $\gamma\left(1+\cos \left(\theta_{\text {rec }}\right)\right)$, where $\gamma$ is the surface tension of water and $\theta_{\text {rec }}$ is the receding contact angle. Increasing surface roughness can either decrease ice adhesion by trapping air pockets between ice and the surface ${ }^{21}$ or increase adhesion by providing more sites for the nucleated ice to mechanically interlock with the substrates. ${ }^{22-26}$ Ice adhesion strength also depends on the stiffness of the substrate; soft material typically reduce ice adhesion by promoting crack initiation at the ice-substrate interface. ${ }^{27-31}$ When contacting a metal or a dielectric material, electrostatic force is the main contributor to ice adhesion. ${ }^{15,32-36}$ For surfaces with hydroxyl groups, hydrogen bonding between ice and substrate dominates, with insignificant contribution from van der Waals' interactions. ${ }^{37-40}$ Adding surfactants (such as polyglycerol to water) can reduce the ice adhesion strength, as the surfactants adsorb onto the surface (such as copper) and reduce the work of adhesion. ${ }^{41,42}$

For freezing in porous structures formed by packed solid particles, water is typically classified into 3 categories: (1) free water (almost the same as bulk water); (2) slightly bound water that freezes at temperature slightly below the freezing point of water $\left(0{ }^{\circ} \mathrm{C}\right)$; $(3)$ strongly bound water that does not freeze even at $-100{ }^{\circ} \mathrm{C}$. The freezing point of water in confined space is determined by the size and shape of the pores, based on surface thermodynamics on microscopic scale. ${ }^{43}$ When the pore size decreases, the expected freezing point of pore water also decreases. For example, the freezing point of water in porous silica glass was estimated to decrease from $-1{ }^{\circ} \mathrm{C}$ to $-9{ }^{\circ} \mathrm{C}$ when the pore size ranged from 1 to $0.01 \mu m .{ }^{44}$

In the mixtures of solid particles and two immiscible fluids, capillary network forms 
between the particles in suspension. ${ }^{45}$ Depending on the fraction of liquid wetting the particle surface, the mixture is stabilized in a pendular or capillary state. However, whether the capillary bridges of interstitial water correlates with the adhesion of granular materials on solid surfaces remains unclear.

Among granular matters in nature, oil sands have complex compositions, typically consisting of 80 to $90 \mathrm{wt} \%$ sand (including silica, clay, and other minerals), 8 to $13 \mathrm{wt} \%$ of heavy oil bitumen (saturates, aromatics, resins, and asphaltenes), ${ }^{46,47}$ and 2 to 8 wt\% of water. ${ }^{47-50}$ Water is mainly sandwiched between hydrophilic sand surface and hydrophobic bitumen, ${ }^{51}$ so bitumen can be separated from solids by warm water extraction in surface mining operations. ${ }^{48,49}$ Strong adhesion of oil sands at low temperature creates problems for mining fleet management. The large carryback of oil sands after unloading reduces the transport capacity and causes extra time and cost for removing oil sands deposits from the truck surface. One may intuitively attribute adhesion of oil sands to heavy species in bitumen, in particular asphaltenes that are well-known to 'glue' firmly onto almost all kinds of solid surfaces, due to strong $\pi-\pi$ interactions and colloidal aggregation. ${ }^{52}$

In this work, we will show that the strong adhesion of oil sands at low temperature $(0$ ${ }^{\circ} \mathrm{C}$ to $-20{ }^{\circ} \mathrm{C}$ ) is determined by freezing of water in oil sands. With x-ray micro-computed tomography (micro-CT), between the sand particles and the solid substrate, we observed water capillary bridges, which contribute to adhesion strength when frozen. We identified a linear relationship between the adhesion strength and the water content in oil sands, based on the local contact area between ice and the solid surface. The insights from our study can help mitigate fouling from oil sands in winter. To the best of the authors' knowledge, this research work is the first study about the adhesion of a frozen granular matter to solid substrates, which may have wider applicability to many natural and industrial processes. 


\section{Materials and Methods}

\section{Preparation and characterization of substrates}

Calibration of the device for adhesion strength measurements was performed by using a slab of polydimethylsiloxane (PDMS), as ice adhesion on PDMS has been extensively studied in literature. ${ }^{27-31}$ To fabricate the PDMS slab, a base and a curing agent (Sylgard 184, Dow Corning) were mixed rigorously at a weight ratio of 10:1 and cast onto a clean glass slide (70 $m m \times 20 \mathrm{~mm})$ to fully cover the slide surface. After degassing in vacuum for 30 minutes, the glass slide coated with PDMS resin was transferred into an oven to cure at $80{ }^{\circ} \mathrm{C}$ for 2 hours. The thickness of the PDMS slab formed on the glass slide was around $1 \mathrm{~mm}$. Before use, the PDMS slab was rinsed with acetone (>99.5\%, Fisher), ethanol (>99\%, Fisher), and deionized water. Reagents (acetone and ethanol) were used as received without any further treatment.

Two solid substrates were used for oil sands adhesion strength $\left(\tau_{a d}\right)$ measurements: stainless steel 304 (McMaster-Carr, USA) with thermal conductivity of 14 to $15 \mathrm{~W} / \mathrm{m} \cdot \mathrm{K}^{53,54}$ and oil-resistant Buna-N nitrile rubber (McMaster-Carr, USA) with thermal conductivity of around $0.25 \mathrm{~W} / \mathrm{m} . K{ }^{55,56}$ The steel and rubber substrates were cut into square-shaped plates with the dimensions of $40 \mathrm{~mm} \times 40 \mathrm{~mm}$, and a thicknesses of 0.76 and $1.6 \mathrm{~mm}$, respectively. The substrates were rinsed consecutively in acetone, ethanol, and water to clean the surface thoroughly before each experiment.

To simulate the industrial scenario where substrates are commonly fouled by bitumen and asphaltene in oil sands, the steel substrate was coated with bitumen/asphaltene. Bitumen used in this study was provided by an oil sands operator in northern Alberta, while n-pentane precipitated asphaltene was supplied by Quadrise Canada Corporation. Bitumen and asphaltene were first dissolved in toluene ( $>99.5 \%$, Fisher) to achieve the same concentration of $250 \mathrm{mg} / \mathrm{mL}$, and were homogenized by sonicating the solution for $15 \mathrm{~min}$. To coat the steel, $0.75 \mathrm{~mL}$ of the bitumen or asphaltene solution was deposited on a steel plate, 
which was then spun at 600 revolutions-per-minute (RPM) for 30 sec on a spin coater (WS$650 \mathrm{Mz}$, Laurell, USA). After spin coating, the coated substrates were placed under ambient condition for 2 days to ensure complete evaporation of the solvent. The coated substrates were rinsed with water before use. The thicknesses of the bitumen and asphaltene coatings were determined to be 30-50 $\mu \mathrm{m}$ as measured by using an optical microscope.

The contact angles of water on the substrates were determined by using a contact angle instrument (DSA100 system, Kruss, USA). The advancing and receding contact angles of water are shown in Table 1.

Table 1: Contact angle of water on substrates

\begin{tabular}{llll}
\hline Substrate & Advancing angle $\left(^{\circ}\right)$ & Receding angle $\left(^{\circ}\right)$ & Hysteresis $\left(^{\circ}\right)$ \\
\hline Stainless steel & $92 \pm 2$ & $21 \pm 4$ & 71 \\
Rubber & $109 \pm 3$ & $58 \pm 3$ & 51 \\
Bitumen-coated steel & $102 \pm 3$ & $43 \pm 4$ & 51 \\
Asphaltene-coated steel & $96 \pm 2$ & $55 \pm 4$ & 41 \\
\hline
\end{tabular}

\section{Preparation of oil sands samples}

Oil sands, which were provided by the same operator as the one for our bitumen sample, were homogenized and stored in sealed plastic bags at $-18^{\circ} \mathrm{C}$ to keep the samples consistent for all the experiments. Before use, the sample was thawed at room temperature overnight. The composition of the oil sands samples was determined by a set of standard Dean-Stark apparatus, under the standard procedure in literature. ${ }^{49,57}$ The samples used in this study naturally contained 4 wt $\%$ of water, 13 wt $\%$ of bitumen and 83 wt $\%$ of solids. To prepare oil sands with higher water weight percentage $\left(C_{w}\right)$, a certain volume of deionized water was added with micro-pipettes and homogenized manually. To prevent water evaporation, the prepared samples with certain water contents were sealed with a paraffin film till the measurements. The composition of the oil sands used in this study is shown in Table 2 . 
Table 2: Composition of oil sands samples (wt\%)

\begin{tabular}{lll}
\hline Water & Bitumen & Solids \\
\hline 4.0 & 13.0 & 83.0 \\
6.0 & 12.7 & 81.3 \\
8.0 & 12.5 & 79.5 \\
10.0 & 12.2 & 77.8 \\
12.0 & 11.9 & 76.1 \\
14.0 & 11.6 & 74.4 \\
\hline
\end{tabular}

\section{Micro-CT scanning of oil sands}

To evaluate the microstructures of oil sands, we scanned the samples with $C_{w}$ of 4 and 14 wt\%. An X-ray micro-CT system (ZEISS Xradia Versa 620 X-Ray Microscope, Zeiss, Germany) was used and the CT scans were performed under ambient condition. Around $0.3 \mathrm{~g}$ of oil sands were confined in a polypropylene cylindrical tube (sample holder) with an inner diameter of $7.2 \mathrm{~mm}$ and a cross-sectional area of $\sim 40 \mathrm{~mm}^{2}$ and was put on the steel substrate. A load of $250 \mathrm{~g}$, equivalent to a pressure of around $60 \mathrm{kPa}$, was applied to the oil sands on a homemade stage (pressure control unit). The pressure is larger than the maximum load experienced by the area on the truck with most carryback after dumping.

The X-ray source was operated at a voltage of $80 \mathrm{kV}$ and a current of $126 \mu \mathrm{A}$ for 5 to 6 hours per scan. The spatial resolution of the micro-CT scanning is $4.25 \mu \mathrm{m} / \mathrm{pixel}$. With the high contrast in the obtained images, we were able to differentiate the compositions of oil sand samples into 3 parts: solids, liquids (bitumen and water), and air. The microstructure of solid/liquid/air phase and the volume fraction of those phases were analyzed using Dragonfly Pro software (Object Research Systems, Canada).

\section{Quantitative measurements of frozen oil sand adhesion}

The adhesion strength of oil sands on solid substrates was measured using a custom-built setup (Figure 1(a)), adapted from the methodologies for ice adhesion measurements in literature. ${ }^{17,58}$ A ceramic Peltier plate was used to control the temperature of the substrate. 
(a)

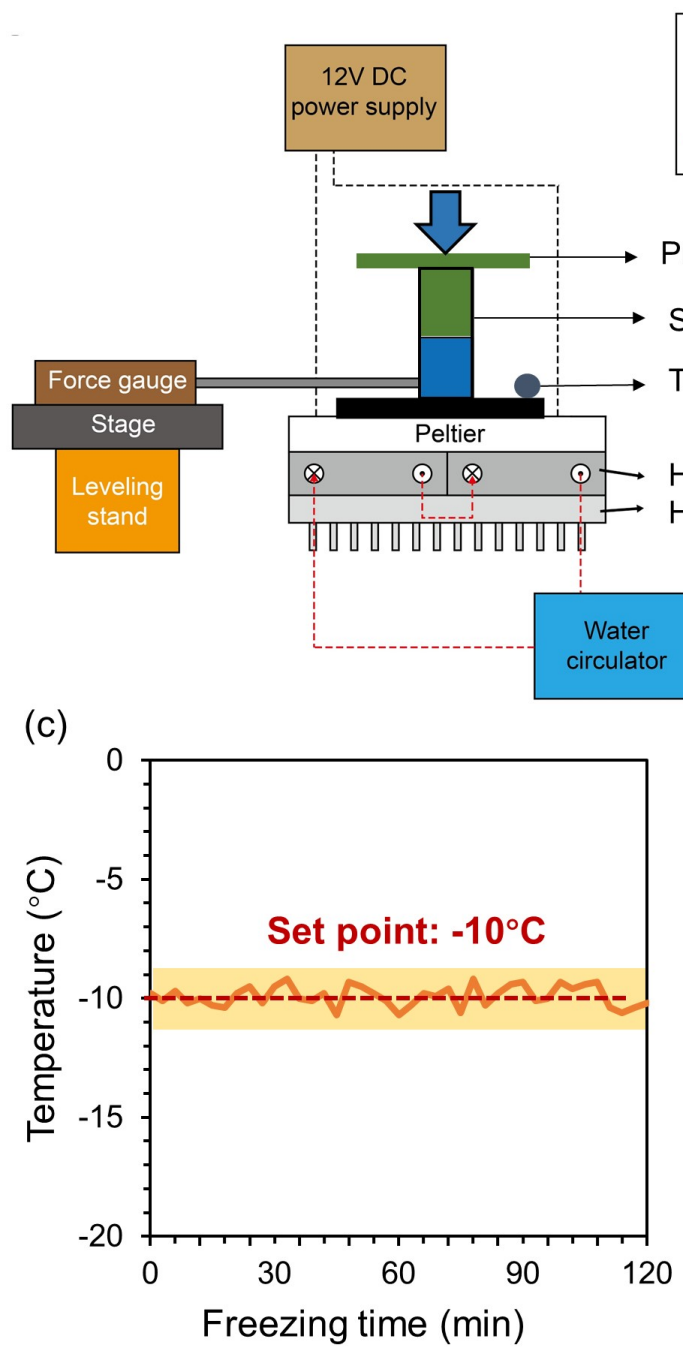

(b)

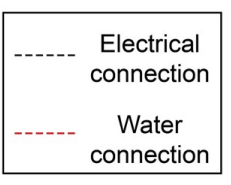

Pressure control unit

Sample holder

Thermocouple

Heat exchanger

Heat sink

Force gauge probe

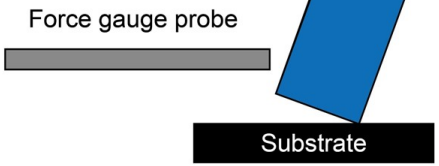

(d)

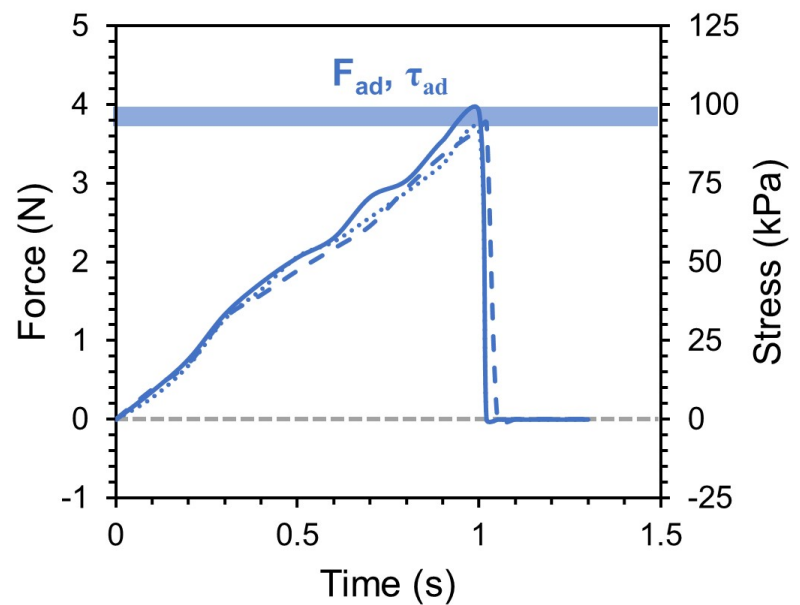

Figure 1: Adhesion strength measurement device and test procedure. (a) Schematic of the setup. (b) A force gauge measures the force applied to the frozen oil sand to the point of detachment. (c) Representative temperature curve on the Peltier stage around the set point temperature of $-10{ }^{\circ} \mathrm{C}$ (denoted as the red dashed line, with the variation indicated by the yellow band). (d) Force/stress curves during the ice adhesion strength measurements on PDMS substrate (3 repeats). The blue band shows the variation of the detaching force $\left(F_{a d}\right) /$ adhesion $\operatorname{strength}\left(\tau_{a d}\right)$ of ice from PDMS substrate.

The heat produced on the opposite face of the Peltier plate was continuously removed by a water circulation system and a fin-type heat sink. The substrate was attached to the Peltier plate via thermally-conductive double sided tape, and a thermocouple was connected to the substrate to monitor the temperature. 
About $0.3 \mathrm{~g}$ of oil sands was placed into the sample holder (same as the one used for CT scan). Then, a pressure of $60 k P a$ was applied on the sample with the pressure control unit (also the same as the one for CT scan). The load was kept on the sample for a preset freezing time, beginning from the moment when the substrate reached the target temperature. During the freezing process, the temperature of the substrate remained within $\pm 1^{\circ} \mathrm{C}$ of the set-point, as monitored by the thermocouple (Figure 1(c)). The load was removed before a force was applied to push the frozen sample.

Figure 1(b) shows the detaching process of the samples from the substrates. To apply a force parallel to the substrate, a force gauge probe attached to a linear motor was placed $<2$ $m m$ above the substrate. The short distance enabled minimal torque applied to the sample before detachment. ${ }^{58}$ Figure $1(\mathrm{~d})$ shows the force curves from three repeated measurements of ice adhesion strength on PDMS substrates after freezing water in the sample holder at $-10{ }^{\circ} \mathrm{C}$ for $30 \mathrm{~min}$. As the linear motor moves at a constant speed of $0.7 \mathrm{~mm} / \mathrm{s}$, the applied force increases linearly with time at $4 \mathrm{~N} / \mathrm{s}$ until it reaches the minimal force required to detach the ice column at which point the force falls back to zero. The minimal detachment force $F_{a d}$ for the three repeats are highly reproducible. The adhesion strength $\tau_{a d}$ obtained by normalizing the force by the contact area of $40 \mathrm{~mm}^{2}$ was $95 \pm 6 \mathrm{kPa}$, within the reported literature values of 70 to $100 \mathrm{kPa}$ under similar experimental conditions. ${ }^{27-31}$ The good reproducibility of the adhesion strength suggests the reliability of our methodology.

\section{Results and discussion}

\section{Oil sands microstructure}

The microstructures of oil sands are characterized using X-ray micro-CT scanning. The images in Figure 2.(a) and (b) show the horizontal cross sections for $C_{w}=4$ and $14 \mathrm{wt} \%$ close to the solid substrate $z<0.01 \mathrm{~mm}$. At $C_{w}=4 \mathrm{wt} \%$, we observed large millimetric

air gaps (Figure 2a), whereas at $C_{w}=14 \mathrm{wt} \%$, only submillimetric-sized air gaps remain 

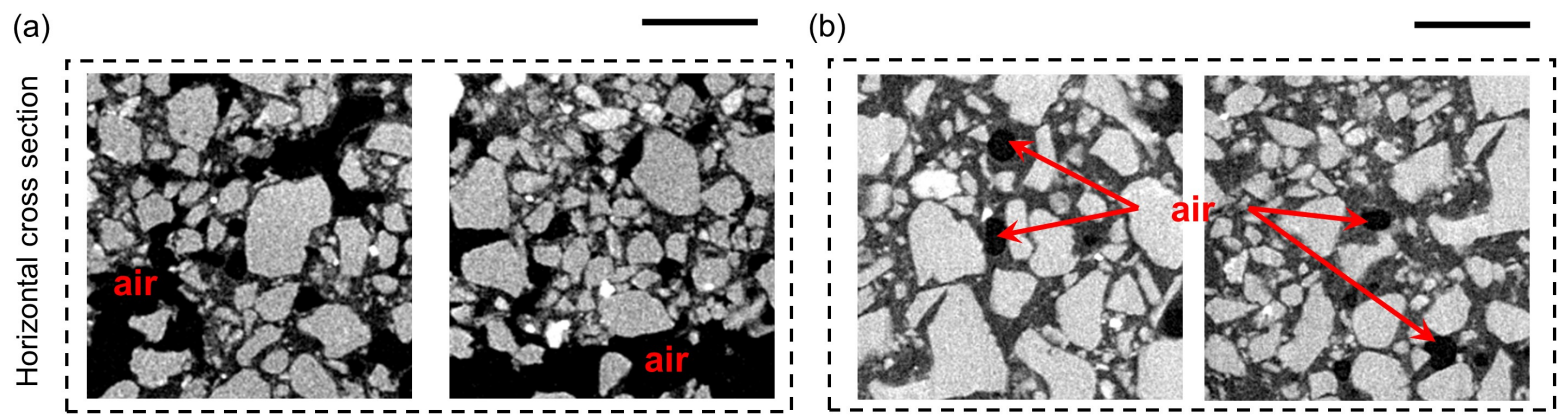

(c)

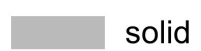
liquid

(d)

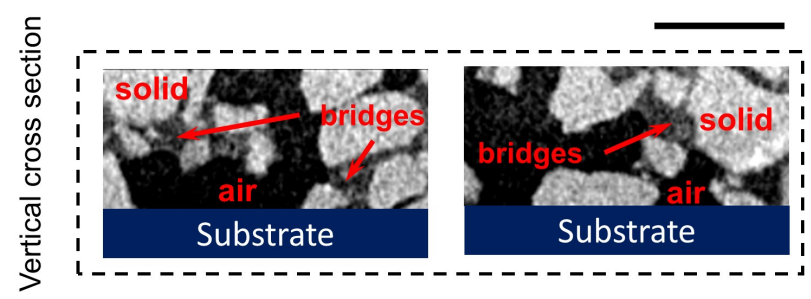

(e)

$4 \mathrm{wt} \%$

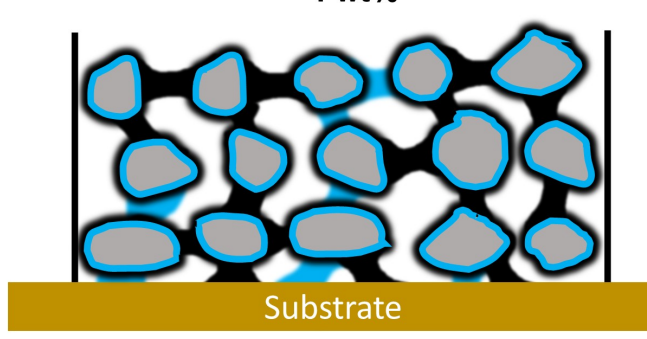

solid

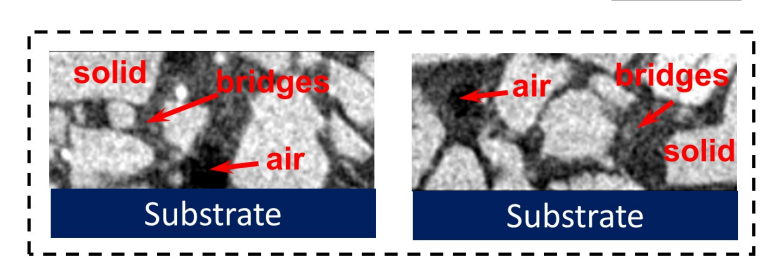

(f)

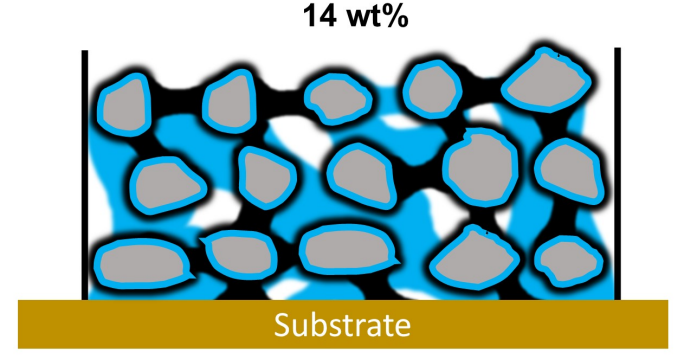

water

bitumen

Figure 2: $(\mathrm{a}, \mathrm{b})$ Horizontal cross section of the oil sands with $C_{w}=4$ and $14 \mathrm{wt} \%$ taken near the substrate $z \approx 0$ using a micro-CT. Scale bars are $0.5 \mathrm{~mm}$. (c, d) The vertical cross section of the same oil sand with $C_{w}=4$ and $14 \mathrm{wt} \%$. The area was picked within the distance range from the substrate of near 0 to $0.25 \mathrm{~mm}$. Scale bars are $0.25 \mathrm{~mm}$. (e, f) Oil sand is a wet granular matter with solid sand particles held together by liquid (bitumen and water) capillary bridges. Increasing water content results in a more compact structure with fewer air gaps.

(Figure 2b). A video from stacking of images is provided in supporting information. We were able to distinguish the solid, liquid and air phases, and their relative compositions are summarized in Table 3. Note that we are not able to distinguish between bitumen and water, because their densities are close to each other, both around $1.0 \mathrm{~g} / \mathrm{cm}^{3} .{ }^{59}$

At $C_{w}=4 \mathrm{wt} \%$, the sand particles (about $55 \mathrm{v} \%$ ) are presumed to be held together by mostly bitumen capillary bridges (due to the low water content), with significant amount (about $25 \mathrm{v} \%$ ) of air. The air gaps gets filled up as more water is mixed with oil sands, 
Table 3: Compositions of oil sand samples after compression at $60 \mathrm{kPa}$. z: the distance from the substrate.

\begin{tabular}{lllll}
\hline \multirow{2}{*}{$C_{w}(\mathrm{wt} \%)$} & $z(\mathrm{~mm})$ & \multicolumn{3}{c}{ Volume fraction(\%) } \\
\cline { 3 - 5 } & & Solids & Liquids & Air \\
\hline \multirow{2}{*}{4} & $0-0.25$ & 54.2 & 21.8 & 24.0 \\
& $0.25-0.50$ & 54.9 & 18.9 & 26.2 \\
\hline \multirow{2}{*}{14} & $0-0.25$ & 56.3 & 34.5 & 9.2 \\
& $0.25-0.50$ & 55.7 & 36.5 & 7.8 \\
\hline
\end{tabular}

resulting in a more compact microstructure. Increasing $C_{w}$ from 4 to $14 \mathrm{wt} \%$ reduces the volume of air gaps by a similar percentage from about $25 \mathrm{v} \%$ to less than $10 \mathrm{v} \%$. The sand particles are held together by water or bitumen capillary bridges. As the silica particles are cloaked by bitumen layer, ${ }^{51}$ we do not expect water to displace the bitumen bridges because of the highly viscoelastic nature of bitumen at the temperature range in the experiments. Images of vertical cross sections also reveal the formation of capillary bridges linking the sand particles and the solid substrate when increasing water content from $C_{w}=4 \mathrm{wt} \%$ (Figure 2 (c)) to $C_{w}=14 \mathrm{wt} \%$ (Figure $2(\mathrm{~d})$ ).

Based on the micro-CT results, we proposed a model of oil sands microstructures after compression. A small amount of water that mainly distributes around the oil sand particles forms a thin hydration layer around the hydrophilic silica surface, as depicted in the schematic in Figure 2(e). ${ }^{51}$ The sand particles are polydisperse with sizes ranging from tens to hundreds of microns and are held together by liquid (mostly bitumen) capillary bridges and with significant amount of air gaps. Increasing the water content (from 4 to 14 wt\%) results in a more compact structure with smaller air gaps as the water occupies some of the pore spaces(Figure 2 (f)), perhaps similar to the transition from the pendular to funicular state in wet granular matter. ${ }^{45}$

With the model above, we propose that at low temperatures, the adhesion between oil sand sample and a solid substrate comes from 5 types of substances: sand particles, air, ice, unfrozen water and bitumen. Among them, the interaction between air and the substrate is 
almost negligible, but that between ice and the substrate is the strongest. We anticipate that there will be an increase of surface area covered by water bridges at the oil sands-substrate interface with water content from 4 to $14 \mathrm{wt} \%$. When frozen, the contact area of water and the substrate may contribute significantly to the adhesion strength of oil sands.

\section{Oil sands adhesion in the limit of short freezing time}
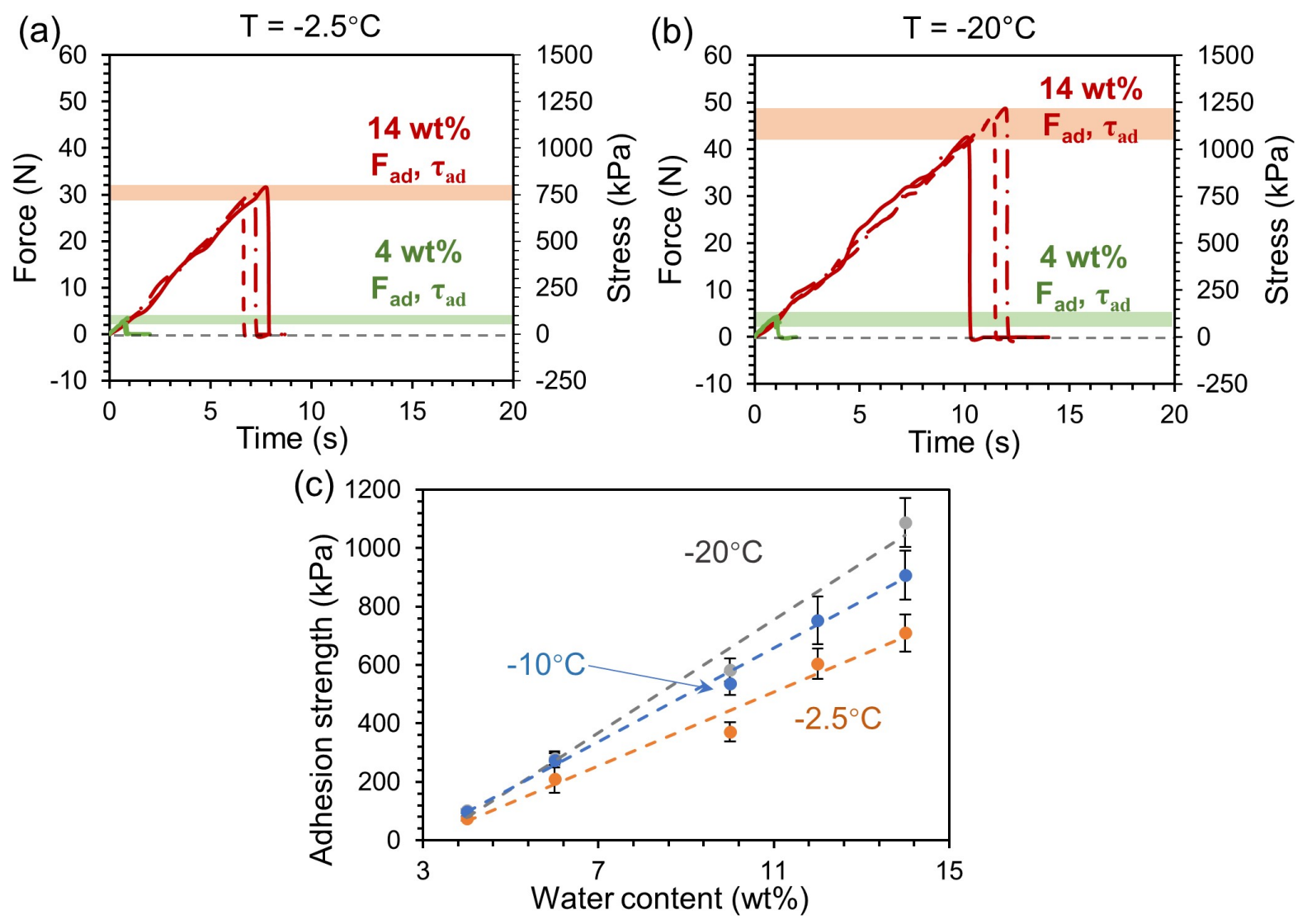

Figure 3: $\tau_{a d}$ of oil sands with $C_{w}=4-20 \mathrm{wt} \%$ on steel substrate after 5 min of freezing. (a, b) Force curves at $T=-2.5{ }^{\circ} \mathrm{C}$ and $-20{ }^{\circ} \mathrm{C}$, respectively, with 3 repeats for each $C_{w}$ value. (c) $\tau_{a d}$ is as a function of $C_{w}$. Error bars in (c) are standard deviations for 5 repeats. The adhesion strength $\tau_{a d}$ was calculated by normalizing $F_{a d}$ by the contact area of $40 \mathrm{~mm}^{2}$.

We first observed that at temperatures $T>0{ }^{\circ} \mathrm{C}$ the adhesion of oil sands to steel was below the measurable limit of $2 k P a$, regardless of the water content $C_{w}=4$ to 20 wt $\%$. The minimal detaching force $F_{a d}$ became measurable after a short freezing time $t=5$ min. Figures $3(\mathrm{a})$ and (b) show the force curves for $C_{w}=4$ and 14 wt\% obtained at $T=-2.5{ }^{\circ} \mathrm{C}$ 
and $-20{ }^{\circ} \mathrm{C}$, respectively.

As $C_{w}$ increased from 4 to 14 wt $\%$ at $T=-2.5{ }^{\circ} \mathrm{C}, \tau_{a d}$ increased by almost 10 times from $74 \pm 7 \mathrm{kPa}$ to $710 \pm 60 \mathrm{kPa}$. The same magnitude of increase in $\tau_{a d}$ was observed also at $T=-10{ }^{\circ} \mathrm{C}$ (from $97 \pm 6 \mathrm{kPa}$ to $910 \pm 80 \mathrm{kPa}$ ) and at $\mathrm{T}=-20{ }^{\circ} \mathrm{C}$ (from 107 $\pm 12 \mathrm{kPa}$ to $1,090 \pm 90 \mathrm{kPa}$ ). At a given temperature, the adhesion strength increases approximately linearly with the increase in water contents (Figure 3 (c)). This implies that ice formation at the sample-substrate interface is key to understanding the strength of oil sands adhesion at low temperatures, with the solid, bitumen and air components contributing little to adhesion strength. Note that even at the highest water content level $\left(C_{w}=14 \%\right)$ and lowest temperature tested $\left(T=-20^{\circ} \mathrm{C}\right)$, the measured $\tau_{a d} \approx 1,100 \mathrm{kPa}$ is still lower than the $\tau_{a d}=1,250 \mathrm{kPa}$ previously reported for pure ice on steel, ${ }^{60,61}$ reflecting the fact that surface ice coverage in oil sands is lower compared to the case of pure ice.

The approximate linear relationship between the adhesion strength and water contents may be rationalized by the contact area of ice and the substrate surface. As discussed in the previous section, there are water capillary bridges connecting the oil sand and the surface, which can freeze when $T<0{ }^{\circ} \mathrm{C}$. The contact area of water capillary bridges $A_{\text {water }}$ (and hence of ice contact area $A_{\text {ice }}$ after freezing) should increase linearly with $C_{w}$. Hence, we expect $F_{a d}$ and $\tau_{a d}$ to increase linearly with $C_{w}$, as we observed experimentally in Fig. 3(c).

The short freezing time $t=5 \mathrm{~min}$ may not be enough for all the water to freeze completely. The measured $\tau_{a d}$ values in Figure 3 may therefore not be equilibrium values, hence allowing us to understand the effects from ice nucleation rate on the adhesion strength of oil sands. From classical nucleation theory, we expect the ice nucleation rate $(J)$ to be given by the Arrhenius equation ${ }^{62}$

$$
J=A \cdot \exp \left(-\frac{\Delta G}{K_{B} T}\right)
$$


where $A$ is the pre-exponential factor, $K_{B}$ is the Boltzmann's constant, $T$ (in Kelvin) is the absolute temperature. The activation energy $\Delta G$ is given by ${ }^{62}$

$$
\begin{aligned}
\Delta G & =\frac{16 \pi}{3} \frac{\gamma^{3}}{\Delta S^{2} \Delta T^{2}} f(\theta) \\
& =\frac{16 \pi}{3} \frac{\gamma^{3} T_{m}^{2}}{L_{v}^{2} \Delta T^{2}} f(\theta)
\end{aligned}
$$

$\gamma\left(\approx 20 \mathrm{mN} \mathrm{m}^{-1}\right)$ is the water-ice interfacial energy, $\Delta S\left(=L_{v} / T_{m}\right)$ is the entropy of fusion, with $L_{v}$ of $3.34 \times 10^{8} \mathrm{~J} \mathrm{~m}^{-3}$ (the specific latent heat of fusion for ice) and $T_{m}$ of 273.15 $K$ (the melting point for ice), and $\Delta T\left(=T-T_{m}\right)$ is the degree of supercooling. $f(\theta)$ is a geometrical factor that depends on the contact angle of water on steel. ${ }^{63}$

$$
f(\theta)=\frac{(2+\cos \theta)(1-\cos \theta)^{2}}{4} \approx 3 \times 10^{-3}
$$

From the measured receding contact angel of water on steel substrate, which is approximately $20^{\circ}$, we estimated $f(\theta)$ to be $3 \times 10^{-3}$ in our experiments. Thus, Eq.(1) and (2) can be rearranged to

$$
\begin{aligned}
J & =A \cdot \exp \left(-\frac{C}{\Delta T^{2}}\right) \\
C & =\frac{16 \pi}{3} \frac{\gamma^{3} T_{m}^{2}}{L_{v}^{2} K_{B} T} f(\theta) \\
& \approx \frac{16 \pi}{3} \frac{\gamma^{3} T_{m}}{L_{v}^{2} K_{B}} f(\theta)=2.7 K^{2}
\end{aligned}
$$

The ice nucleation rate $(J)$ is therefore highly dependent on $\Delta T$, with a constant $C \approx$ $2.74 K^{2}$ that depends on the material properties of oil sands and the substrate.

To verify that $\tau_{a d} \propto A_{\text {ice }} \propto J$, we varied $T$ from -2.5 to $-20{ }^{\circ} \mathrm{C}$ and measured $\tau_{a d}$ while keeping the freezing time constant at $5 \mathrm{~min}$. Indeed, $\tau_{a d}$ increases with increasing $\Delta T$ for all 

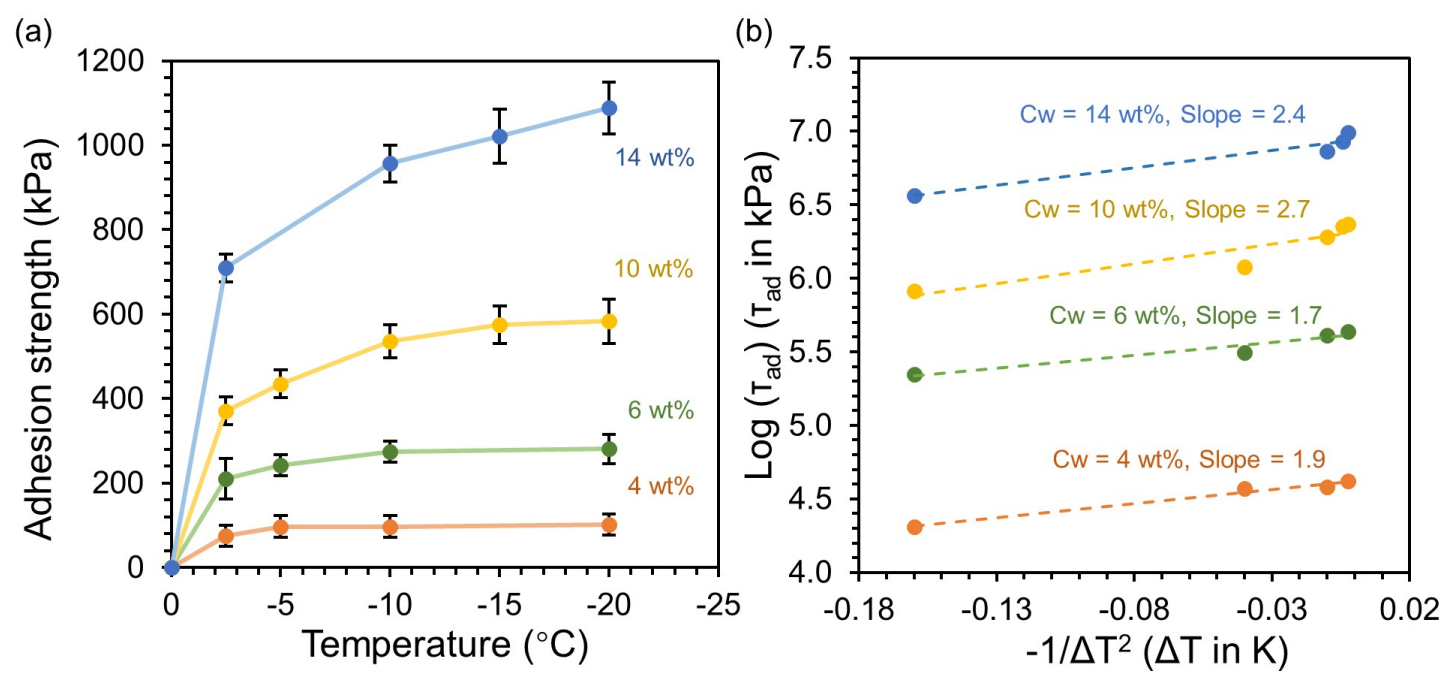

Figure 4: (a) $\tau_{a d}$ of oil sand samples with different $C_{w}$ to steel as a function of $T$ after 5 min of freezing time. At $T=0{ }^{\circ} \mathrm{C}, \tau_{a d}$ is too low to be measured for all $C_{w}$ levels. Lines are guides to the eye. Error bars are standard deviations for 3 to 5 repeats. (b) Plot of $\log \left(\tau_{a d}\right)$ against $1 / \Delta T^{2}$ for the same data in (a). $\tau_{a d}$ and $\Delta T$ have units of $\mathrm{kPa}$ and $\mathrm{K}$, respectively.

$C_{w}$ values (Figure 4.(a)). Plotting $\log \tau_{a d}$ against $-1 / \Delta T^{2}$ also results in straight lines with slopes ranging from 1.7 to $2.7 \mathrm{~K}^{2}$, close to the expected $C$ value as predicted by Equation 4 (Figure 4.(b)). In the limit of short freezing time, the adhesion strength is therefore limited by the ice nucleation rate and hence the degree of supercooling $\Delta T$. In contrast, with longer freezing time, the adhesion strength approaches the equilibrium value and no longer depends on $\Delta T$, as will be discussed in the next section.

\section{Oil sands adhesion in the limit of long freezing time}

To evaluate the effect of freezing temperature and $C_{w}$ on $\tau_{a d}$ after longer freezing time, we increased the freezing time from 5 to $60 \mathrm{~min}$. Figure 5 shows that $\tau_{a d}$ reached equilibrium after sufficient freezing time. At $T$ of $-5{ }^{\circ} \mathrm{C},-10{ }^{\circ} \mathrm{C}$, and $-20{ }^{\circ} \mathrm{C}, \tau_{a d}$ always reached the same plateaued value of $\sim 950 \mathrm{kPa}$. Here, the water concentration was kept at $C_{w}$ of $10 \mathrm{wt} \%$. The time for $\tau_{a d}$ to plateau $\left(\mathrm{t}_{\text {plateau }}\right)$ was the shortest at the lowest temperature of $-20{ }^{\circ} \mathrm{C}$ $\left(\mathrm{t}_{\text {plateau }} \sim 10 \mathrm{~min}\right.$ ), which doubled to $\sim 20 \mathrm{~min}$ at $-10{ }^{\circ} \mathrm{C}$ and tripled to $\sim 30 \mathrm{~min}$ at $-5{ }^{\circ} \mathrm{C}$. The same $\tau_{a d}$ at three test temperatures suggests that $\tau_{a d}$ may not be limited by nucleation 

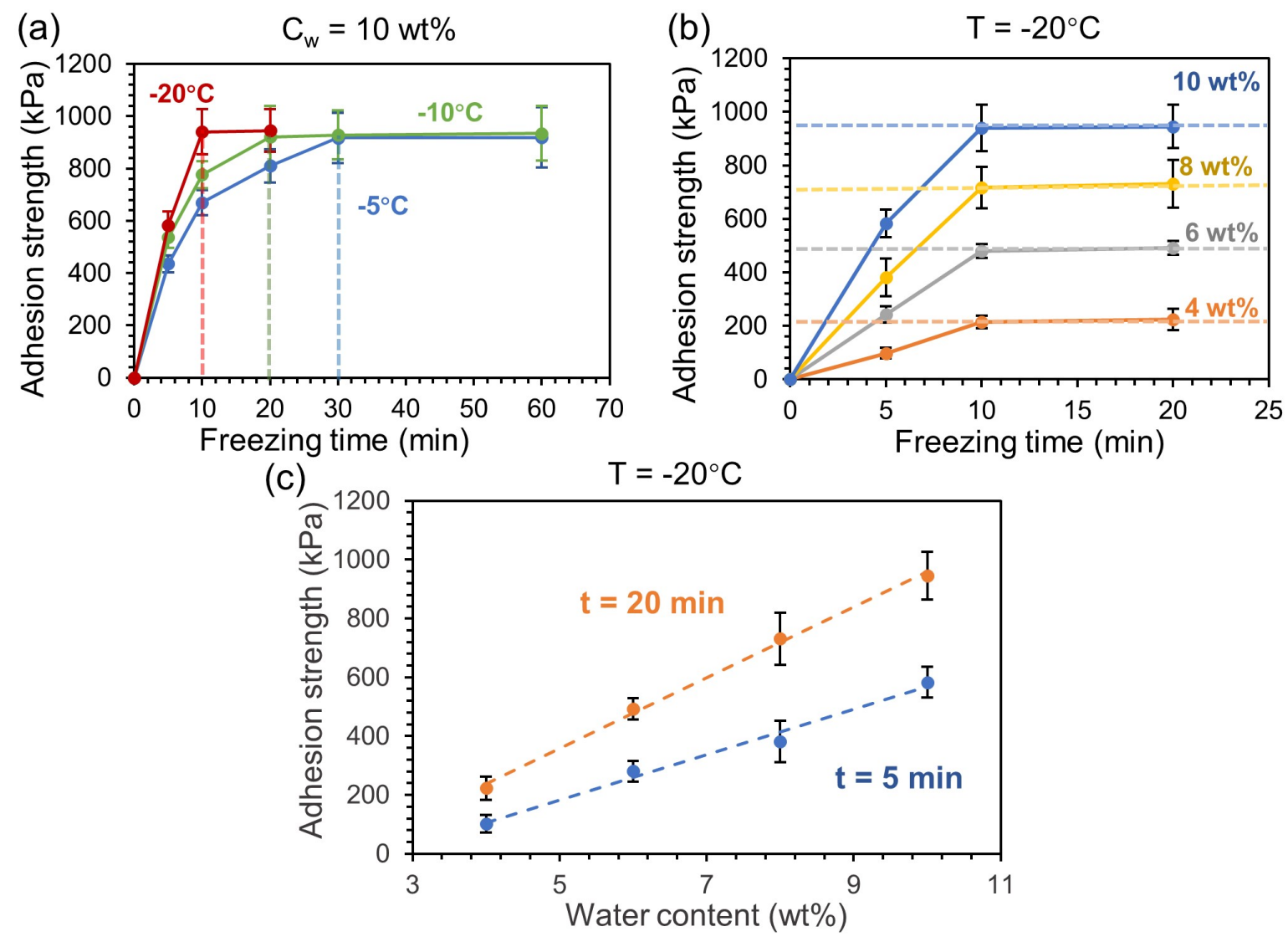

Figure 5: Equilibrium $\tau_{a d}$ after longer freezing time. (a) - Results of oil sands $\tau_{a d}$ with longer freezing time for oil sands with $C_{w} 10 \mathrm{wt} \%$ at $-5{ }^{\circ} \mathrm{C}$ to $-20{ }^{\circ} \mathrm{C}$. Each color of the line denotes the results at a certain temperature. The dashed lines with corresponding color denotes the plateau time; (b) - $\tau_{a d}$ for oil sands with $C_{w}$ of 4 to $10 \mathrm{wt} \%$ at $-20{ }^{\circ} \mathrm{C}$ with 5 to 20 min of freezing time. Each color of the lines denotes a certain $C_{w}$ level. The dashed lines of corresponding color label out the plateau for a $C_{w}$ level; (c) - Results of linear fitting for $\tau_{a d}$ and $C_{w}$ at $-20{ }^{\circ} \mathrm{C}$ with 5 and 20 min of freezing time. Error bars show the standard deviation from 3 to 5 repeated tests.

rate after long freezing time. In this case, all the water in oil sands that can be frozen may determine $\tau_{a d}$ at the plateau.

Figure 5.(b) shows the plateau adhesion strength varies with water content in oil sands. The adhesion strength of oil sand samples changed with time at $-20{ }^{\circ} \mathrm{C}$. For the first $10 \mathrm{~min}$ of freezing, the adhesion strengths of all the samples $\left(C_{w}\right.$ from 4 to $\left.10 \mathrm{wt} \%\right)$ increased with freezing time until reaching a plateau. The rate at which adhesion strength increases was higher for samples with more water. After $10 \mathrm{~min}$ of freezing time, the adhesion strength reached the plateau for all the water content levels. Again, the equilibrium adhesion strength 
was higher for samples with a higher water content, which is consistent with the results shown in Figure 3.

The adhesion strength increases linearly with water content for both freezing time of 5 and $20 \mathrm{~min}$ as shown in Figure 5.(c). This result indicated that the ice coverage of oil sand samples increased linearly with $C_{w}$ from 4 wt\% to 14 wt\% given sufficiently long freezing time $(20 \mathrm{~min})$ and at sufficiently low temperature $\left(-20^{\circ} \mathrm{C}\right)$, which also agrees with the model we proposed in Figure 2.

\section{Effects of substrate properties on the adhesion}

To evaluate the influence of substrate property, we measured $\tau_{a d}$ of oil sands on 3 more substrates. Shown in Figure 6.(a), $\tau_{a d}$ increased almost linearly from $24 \pm 9 k P a$ to $125 \pm$ $30 \mathrm{kPa}$ with $C_{w}$ from 4 to $14 \mathrm{wt} \%$ on a rubber substrate at $-10^{\circ} \mathrm{C}$ for $5 \mathrm{~min}$ of freezing time. This result confirms that water content in oil sands is also essential for the rubber substrate, and the model we proposed in Figure 2 is not limited to steel.

Compared with $\tau_{a d}$ on steel substrate under same conditions, $\tau_{a d}$ on rubber substrate was about $15-20 \%$ of the value for oil sands with the given $C_{w}$ level. The softness of the substrate may decrease the oil sands $\tau_{a d}$ on the rubber. ${ }^{27-31}$

In the work of Meuler et al., ${ }^{17}$ researchers found that the ice adhesion strength was proportional to $R=\gamma\left(1+\cos \left(\theta_{\text {rec }}\right)\right)$, which represents the work of detachment of water from the substrate. From Figure 6.(b), the adhesion strength $\tau_{a d}$ increases with $R$ for rubber, asphaltene and bitumen-coated substrates for oil sands with $10 \mathrm{wt} \%$ of water at $-5{ }^{\circ} \mathrm{C}$ for 5 min of freezing time. But there was not a linear relationship between $R$ and $\tau_{a d}$ of oil sands for oil sands. Our results suggest that for short freezing time, the adhesion strength on different substrates cannot be explained only based on ice adhesion. From our discussion above,the adhesion strength of oil sands is related to the ice coverage resulted from freezing of water in oil sands. Within the relatively short freezing time of $5 \mathrm{~min}$, a lower ice nucleation rate is expected on the rubber substrate and coated steel, due to the higher contact angle 

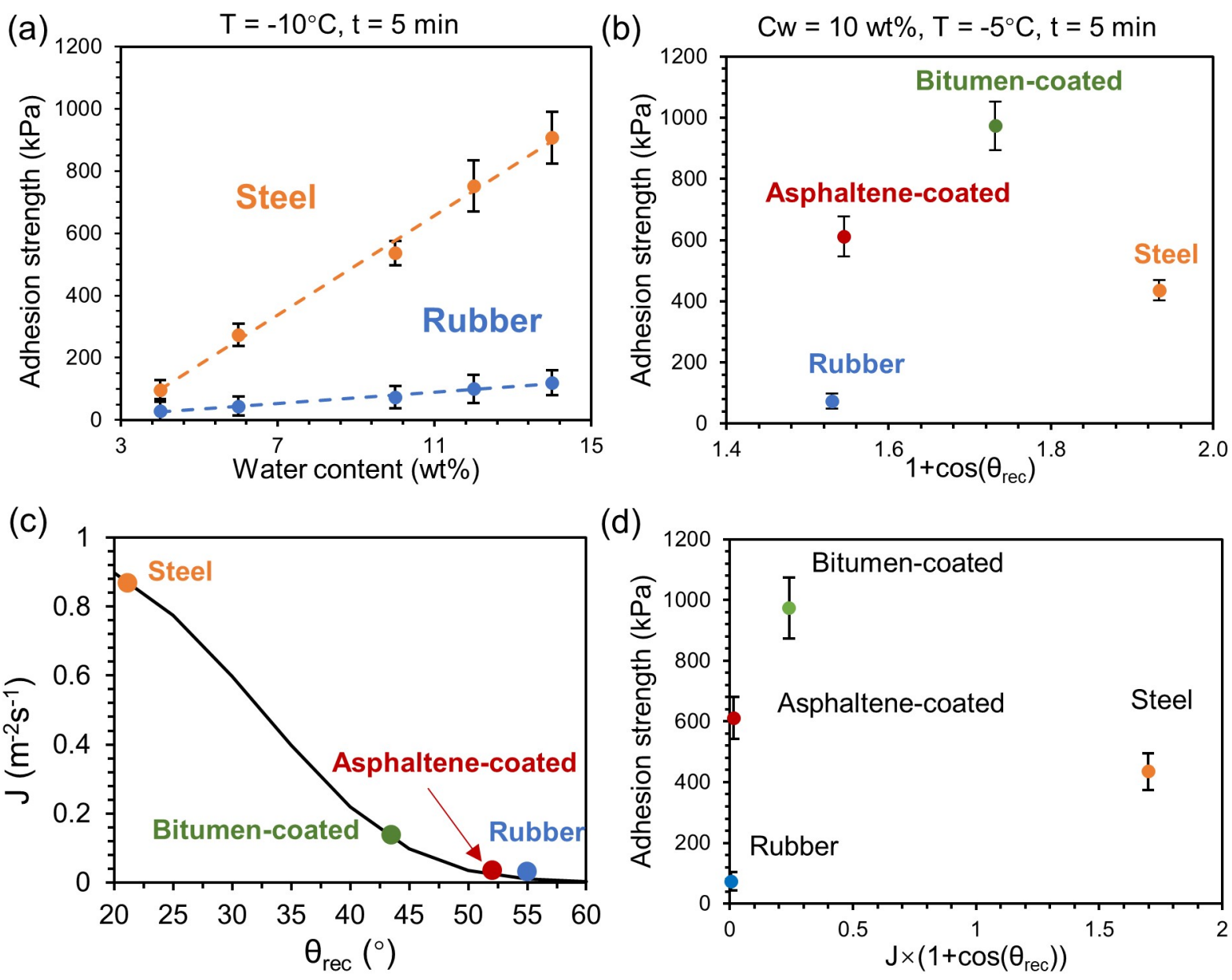

Figure 6: Comparison of $\tau_{a d}$ on steel and other substrates with 5 min of freezing time. (a) $-\tau_{a d}$ of oil sands with $C_{w}$ of 4 to $14 \mathrm{wt} \%$ on steel and rubber substrates at $-5{ }^{\circ} \mathrm{C}$; (b) - Relationship between oil sands $\tau_{a d}$ with receding water contact angle on steel, rubber, and bitumen/asphaltene coated substrates; (c) - Ice nucleation rate changing with receding water contact angle according to Equation 4 at $-5{ }^{\circ} \mathrm{C}$. Pre-exponential factor $A$ was assumed to be $1 \mathrm{~m}^{-2} \mathrm{~s}^{-1}$; (d) - Trend of $\tau_{a d}$ changing with nucleation rate and ice adhesion strength $\left(J \times \cos \left(\theta_{\text {rec }}\right)\right)$ at $-5{ }^{\circ} \mathrm{C}$. Error bars were the standard deviation of 3 to 5 repeated tests.

of water $(\theta)$ in Eq.(4). The lower nucleation rate may lead to a lower $A_{i c e}$ and consequently, lower $\tau_{a d}$. It was reported that the hydrophobicity of the rubber substrate could increase the activation energy and supercooling for ice formation, as the network of hydrogen bonds in water is more disordered near a hydrophobic surface. ${ }^{64}$ A lower nucleation rate is resulted from a larger $f(\theta)$ and larger $C$ in Eq.(4).

Figure $6(\mathrm{c})$ shows the ice nucleation rate $(J)$ for the four substrates based on Equation4 (assuming the pre-exponential factor $A$ equals to $1 \mathrm{~m}^{-2} \mathrm{~s}^{-1}$ ). Taking both nucleation rate 
and ice adhesion into consideration, we found that $\tau_{a d}$ increases with $J \times\left(1+\cos \left(\theta_{\text {rec }}\right)\right)$ for rubber, asphaltene and bitumen coated substrate in Figure 6.(d). However, $\tau_{a d}$ on pristine steel substrate is lower than expected. We suspect that the stiffness and the high roughness of the steel (as evident by the large hysteresis of over $70^{\circ}$ in the contact angle) reduces the contact area and number of capillary bridges on the surface due to the presence of more air pockets at the interface. As the surface layer is smoothed by bitumen or asphaltene coating, there is more direct contact on the surface and thus, higher adhesion strength. Also, for bitumen and asphaltene-coated substrates, the attraction between the coating and bulk bitumen in oil sands (such as $\pi-\pi$ interaction) might enhance the adhesion strength in addition to the influence from surface roughness at low temperatures. ${ }^{52}$

\section{Effective strategy to mitigate oil sands adhesion}

Our results above showed that the ice was the key for the strong adhesion strength of oil sands to solid substrates at low temperature. Thus, our rational design of the approach to mitigating oil sands adhesion is to reduce the contact area of water bridges and prevent water nucleation on solid substrates. To this end, we tried to utilize a commonly used anti-freezing liquid, ethylene glycol (EG, >99.8\%, Sigma), to shield water bridges from the substrate and to reduce the freezing point of water. We measured $\tau_{a d}$ of oil sands on the solid substrates with a pre-deposited layer of EG before applying oil sands and kept all the following procedure the same as we introduced in the previous sections. The conditions of the tests with EG spray and the results of $\tau_{a d}$ are shown in Table 4.

Table 4: Conditions and results of $\tau_{a d}$ measurement with EG spray measured after $2 \mathrm{hr}$ of freezing

\begin{tabular}{cccc}
\hline Substrate & Water content (wt\%) & Temperature $\left({ }^{\circ} \mathrm{C}\right)$ & $\tau_{a d}$ \\
\hline Steel & 4 & -20 & Undetectable \\
Steel & 14 & -10 & Undetectable \\
Steel & 14 & -20 & Undetectable \\
\hline Bitumen-coated & 4 & -20 & Undetectable \\
Bitumen-coated & 14 & -10 & Undetectable \\
Bitumen-coated & 14 & -20 & Undetectable \\
\hline
\end{tabular}


With a sprayed layer of EG (at least 3 repeats under each condition showed in Table 4), interestingly, we found that $\tau_{a d}$ decreased to a value lower than the minimum limit of our setup $(<2 \mathrm{kPa})$. Note that the adhesion strength was ultra low not only on the pristine steel substrate, but also on the bitumen-coated substrate. This impressive result shows that reducing the contact area of water bridges and preventing ice formation are highly effective in mitigating the adhesion of oil sands to solid substrates, even with the presence of bitumen coating. Consequently, the method of spraying anti-freezing liquid can be a possible solution for reducing oil sands adhesion in the oil industry.

\section{Conclusions}

In this work, we found that water content in critical for the adhesion of oil sands (a complex granular matter) at low temperature. The images from our micro-CT measurements show that the air pockets in oil sands was filled with interstitial water, which forms capillary bridges with the substrate. The adhesion strength of oil sands increased linearly on steel and rubber substrate with increase in the water content, and also with the degree of supercooling within a short freezing time. Formation and adhesion of ice was shown to increase the adhesion strength of oil sands. Fouling from bitumen or asphaltene layer on the surface aggravates the adhesion of oil sands on steel. Based on the significant impact from ice in the granular matrix, we developed an effective approach to reducing the adhesion of oil sands by spraying an anti-freezing liquid on the substrate. No adhesion was detected after spraying.

The findings from this work may lead to promising solutions to prevent the accumulation of oil sands on surfaces at low temperature. The fundamental understanding of the adhesion may be applicable to the adhesion of other frozen granular matters on solid substrates. Based on the solutions provided in this work, the efficiency of transportation of oil sands at low temperatures could increase. Meanwhile, the high cost from the labor and energy intensive cleaning process for oil sands stain on surfaces may be reduced. 


\section{Acknowledgement}

The authors acknowledge the funding support from the Institute for Oil Sands Innovation (IOSI) (project number IOSI 2019-11) and from the Natural Science and Engineering Research Council of Canada (NSERC). Part of the research is supported by Canada Reseach Chair program. The authors are grateful for technical support from the IOSI lab, particularly from Xiaoli Tan, Lisa Brandt and Brittany MacKinnon for their help in Dean-Stark experiment training and supervision. We are grateful for Nikoo Moradapour for collecting part of the data of the adhesion strength measurements. We are also grateful for the technical support from Peng Li and Haoyang Yu from NanoFab at University of Alberta for their assistance in the experiments and their advice on the data analysis of X-ray micro-CT scan.

\section{References}

(1) Bockheim, J. Ice core and ice cement effects on soil development, eastern Wright Valley, Antarctica. New Zealand Journal of Geology and Geophysics 1979, 22, 487-493.

(2) George, R. Freezing proceseses used in the food industry. Trends in Food Science $\&$ Technology 1993, 4, 134-138.

(3) Kiani, H.; Sun, D.-W. Water crystallization and its importance to freezing of foods: A review. Trends in Food Science 85 Technology 2011, 22, 407-426.

(4) Kang, T.; You, Y.; Jun, S. Supercooling preservation technology in food and biological samples: A review focused on electric and magnetic field applications. Food science and biotechnology 2020, 29, 303-321.

(5) Qian, L.; Zhang, H. Controlled freezing and freeze drying: a versatile route for porous and micro-/nano-structured materials. Journal of Chemical Technology $\&$ Biotechnology 2011, 86, 172-184. 
(6) Ke, B.; Zhou, K.; Xu, C.; Deng, H.; Li, J.; Bin, F. Dynamic mechanical property deterioration model of sandstone caused by freeze-thaw weathering. Rock Mechanics and Rock Engineering 2018, 51, 2791-2804.

(7) Bolliger, S.; Wildmoser, H.; Goff, H.; Tharp, B. Relationships between ice cream mix viscoelasticity and ice crystal growth in ice cream. International Dairy Journal 2000, 10, 791-797.

(8) Zhang, C.; Zhang, D.; Zhang, M.; Mao, W. Data-driven ship energy efficiency analysis and optimization model for route planning in ice-covered Arctic waters. Ocean Engineering 2019, 186, 106071.

(9) Tran, P.; Brahimi, M.; Paraschivoiu, I.; Pueyo, A.; Tezok, F. Ice accretion on aircraft wings with thermodynamic effects. Journal of Aircraft 1995, 32, 444-446.

(10) Bragg, M.; Hutchison, T.; Merret, J. Effect of ice accretion on aircraft flight dynamics. 38th Aerospace Sciences Meeting and Exhibit. 2000; p 360.

(11) Volat, C.; Farzaneh, M.; Leblond, A. De-icing/anti-icing techniques for power lines: current methods and future direction. Proceedings of the 11th International Workshop on Atmospheric Icing of Structures, Montreal, Canada. 2005.

(12) Jasinski, W. J.; Noe, S. C.; Selig, M. S.; Bragg, M. B. Wind turbine performance under icing conditions. 1998,

(13) Makkonen, L.; Laakso, T.; Marjaniemi, M.; Finstad, K. J. Modelling and prevention of ice accretion on wind turbines. Wind engineering 2001, 25, 3-21.

(14) Bascom, W.; Cottington, R.; Singleterry, C. Ice adhesion to hydrophilic and hydrophobic surfaces. The Journal of Adhesion 1969, 1, 246-263.

(15) Ryzhkin, I. A.; Petrenko, V. F. Physical mechanisms responsible for ice adhesion. The Journal of Physical Chemistry B 1997, 101, 6267-6270. 
(16) Rønneberg, S.; He, J.; Zhang, Z. The need for standards in low ice adhesion surface research: a critical review. Journal of Adhesion Science and Technology 2020, 34, $319-347$.

(17) Meuler, A. J.; Smith, J. D.; Varanasi, K. K.; Mabry, J. M.; McKinley, G. H.; Cohen, R. E. Relationships between water wettability and ice adhesion. ACS applied materials \& interfaces 2010, 2, 3100-3110.

(18) Yeong, Y. H.; Milionis, A.; Loth, E.; Sokhey, J.; Lambourne, A. Atmospheric ice adhesion on water-repellent coatings: wetting and surface topology effects. Langmuir 2015, 31, 13107-13116.

(19) Dotan, A.; Dodiuk, H.; Laforte, C.; Kenig, S. The relationship between water wetting and ice adhesion. Journal of Adhesion Science and Technology 2009, 23, 1907-1915.

(20) Nosonovsky, M.; Hejazi, V. Why superhydrophobic surfaces are not always icephobic. ACS nano 2012, 6, 8488-8491.

(21) Fu, Q.; Wu, X.; Kumar, D.; Ho, J. W.; Kanhere, P. D.; Srikanth, N.; Liu, E.; Wilson, P.; Chen, Z. Development of sol-gel icephobic coatings: effect of surface roughness and surface energy. ACS applied materials \& interfaces 2014, 6, 20685-20692.

(22) Kasaai, M. R.; Farzaneh, M. Evaluation of mechanisms of ice adhesion on power network equipment. International Conference on Offshore Mechanics and Arctic Engineering. 2004; pp 927-932.

(23) Hassan, M.; Lee, H.; Lim, S. The variation of ice adhesion strength with substrate surface roughness. Measurement Science and Technology 2010, 21, 075701.

(24) Chen, J.; Liu, J.; He, M.; Li, K.; Cui, D.; Zhang, Q.; Zeng, X.; Zhang, Y.; Wang, J.; Song, Y. Superhydrophobic surfaces cannot reduce ice adhesion. Applied Physics Letters 2012, 101, 111603. 
(25) Strobl, T.; Raps, D. M.; Hornung, M. Evaluation of roughness effects on ice adhesion. 5th AIAA Atmospheric and Space Environments Conference. 2013; p 2547.

(26) Ling, E. J. Y.; Uong, V.; Renault-Crispo, J.-S.; Kietzig, A.-M.; Servio, P. Reducing ice adhesion on nonsmooth metallic surfaces: wettability and topography effects. ACS applied materials $\&$ interfaces 2016, 8, 8789-8800.

(27) Wang, C.; Fuller, T.; Zhang, W.; Wynne, K. J. Thickness dependence of ice removal stress for a polydimethylsiloxane nanocomposite: Sylgard 184. Langmuir 2014, 30, $12819-12826$.

(28) Beemer, D. L.; Wang, W.; Kota, A. K. Durable gels with ultra-low adhesion to ice. J. Mater. Chem. A 2016, 4, 18253-18258.

(29) Yeong, Y. H.; Wang, C.; Wynne, K. J.; Gupta, M. C. Oil-infused superhydrophobic silicone material for low ice adhesion with long-term infusion stability. ACS Appl. Mater. Interfaces 2016, 8, 32050-32059.

(30) He, Z.; Zhuo, Y.; He, J.; Zhang, Z. Design and preparation of sandwich-like polydimethylsiloxane (PDMS) sponges with super-low ice adhesion. Soft Matter 2018, 14, 4846-4851.

(31) Shen, Y.; Wu, Y.; Tao, J.; Zhu, C.; Chen, H.; Wu, Z.; Xie, Y. Spraying fabrication of durable and transparent coatings for anti-icing application: dynamic water repellency, icing delay, and ice adhesion. ACS applied materials \& interfaces 2018, 11, 3590-3598.

(32) Israelachvili, J. N. Intermolecular and surface forces; Academic press, 2011.

(33) Oksanen, P. Friction and adhesion of ice. 1983,

(34) Fortin, G.; Perron, J. Ice adhesion models to predict shear stress at shedding. Journal of adhesion science and technology 2012, 26, 523-553. 
(35) Petrenko, V. F.; Ryzhkin, I. A. Surface states of charge carriers and electrical properties of the surface layer of ice. The Journal of Physical Chemistry B 1997, 101, 6285-6289.

(36) Xiao, S.; He, J.; Zhang, Z. Modeling nanoscale ice adhesion. Acta Mechanica Solida Sinica 2017, 30, 224-226.

(37) Petrenko, V. F.; Peng, S. Reduction of ice adhesion to metal by using self-assembling monolayers (SAMs). Canadian journal of physics 2003, 81, 387-393.

(38) Matsumoto, K.; Tsubaki, D.; Sekine, K.; Kubota, H.; Minamiya, K.; Yamanaka, S. Influences of number of hydroxyl groups and cooling solid surface temperature on ice adhesion force. International Journal of Refrigeration 2017, 75, 322-330.

(39) Wilen, L.; Wettlaufer, J.; Elbaum, M.; Schick, M. Dispersion-force effects in interfacial premelting of ice. Physical Review B 1995, 52, 12426.

(40) Menini, R.; Farzaneh, M. Advanced icephobic coatings. Journal of adhesion science and technology 2011, 25, 971-992.

(41) Matsumoto, K.; Minamiya, K.; Kubota, H.; Sekine, K. Active control of ice adhesion force to copper surface by varying surfactant concentrations. International Journal of Refrigeration 2017, 76, 252-260.

(42) Matsumoto, K.; Minamiya, K.; Sakamoto, J.; Ueda, J.; Ehara, K.; Yamanaka, S. Temperature-dependency on adhesion force of ice made from surfactant-pure water mixture to copper surface. International Journal of Refrigeration 2017, 79, 39-48.

(43) Elliott, J. A. Surface thermodynamics at the nanoscale. The Journal of Chemical Physics 2021, 154, 190901.

(44) Blachere, J.; Young, J. The freezing point of water in porous glass. Journal of the American Ceramic Society 1972, 55, 306-308. 
(45) Mitarai, N.; Nori, F. Wet granular materials. Adv. Phys. 2006, 55, 1-45.

(46) He, L.; Li, X.; Wu, G.; Lin, F.; Sui, H. Distribution of saturates, aromatics, resins, and asphaltenes fractions in the bituminous layer of athabasca oil sands. Energy $\&$ fuels 2013, 27, 4677-4683.

(47) Nie, F.; He, D.; Guan, J.; Li, X.; Hong, Y.; Wang, L.; Zheng, H.; Zhang, Q. Oil sand pyrolysis: Evolution of volatiles and contributions from mineral, bitumen, maltene, and SARA fractions. Fuel 2018, 224, 726-739.

(48) Hepler, L. G.; Hsi, C. AOSTRA technical handbook on oil sands, bitumens and heavy oils. 1989,

(49) Hooshiar, A.; Uhlik, P.; Liu, Q.; Etsell, T. H.; Ivey, D. G. Clay minerals in nonaqueous extraction of bitumen from Alberta oil sands: Part 1. Nonaqueous extraction procedure. Fuel Process. Technol. 2012, 94, 80-85.

(50) Nikakhtari, H.; Wolf, S.; Choi, P.; Liu, Q.; Gray, M. R. Migration of fine solids into product bitumen from solvent extraction of Alberta oilsands. Energy \& fuels 2014, 28, $2925-2932$.

(51) Czarnecki, J.; Radoev, B.; Schramm, L. L.; Slavchev, R. On the nature of Athabasca oil sands. Advances in Colloid and Interface Science 2005, 114, 53-60.

(52) Adams, J. J. Asphaltene adsorption, a literature review. Energy \& Fuels 2014, 28, $2831-2856$.

(53) Blackwell, B. F.; Gill, W.; Dowding, K. J.; Easterling, R. G. Uncertainty estimation in the determination of thermal conductivity of 304 stainless steel; 2000.

(54) Graves, R. S.; Kollie, T. G.; McElroy, D. L.; Gilchrist, K. E. The thermal conductivity of AISI 304L stainless steel. International journal of thermophysics 1991, 12, 409-415, Publisher: Springer. 
(55) Bhowmick, T.; Pattanayak, S. Thermal conductivity, heat capacity and diffusivity of rubbers from 60 to 300 K. Cryogenics 1990, 30, 116-121.

(56) Pinedo, B.; Hadfield, M.; Tzanakis, I.; Conte, M.; Anand, M. Thermal analysis and tribological investigation on TPU and NBR elastomers applied to sealing applications. Tribology International 2018, 127, 24-36.

(57) Bulmer, J.; Starr, J. Syncrude analytical methods for oil sand and bitumen processing. 1979

(58) Hakimian, A.; Nazifi, S.; Ghasemi, H. Metrology of Ice Adhesion. Ice Adhesion: Mechanism, Measurement and Mitigation 2020, 217-236.

(59) Mochinaga, H.; Onozuka, S.; Kono, F.; Ogawa, T.; Takahashi, A.; Torigoe, T. Properties of Oil sands and Bitumen in Athabasca. The Canadian Society of Exploration Geologists CSPG-CSEG-CWLS Convention. 2006; pp 39-44.

(60) Ozbay, S.; Erbil, H. Y. Ice accretion by spraying supercooled droplets is not dependent on wettability and surface free energy of substrates. Colloids and Surfaces A: Physicochemical and Engineering Aspects 2016, 504, 210-218.

(61) Fillion, R. M.; Riahi, A.; Edrisy, A. Design factors for reducing ice adhesion. Journal of adhesion science and technology 2017, 31, 2271-2284.

(62) Kashchiev, D. Nucleation; Elsevier, 2000.

(63) Maeda, N. Brief Overview of Ice Nucleation. Molecules 2021, 26, 392.

(64) Chandler, D. Interfaces and the driving force of hydrophobic assembly. Nature 2005, $437,640-647$. 